\title{
A morphological analysis of the subtribe Pegylina Lacroix, 1989 (Scarabaeidae: Melolonthinae: Melolonthini) reconstitutes its generic composition
}

\author{
J. du G. Harrison ${ }^{1,2,3}$ \\ ${ }^{1}$ Department of Zoology and Entomology, Forestry and Agricultural Biotechnology Institute, \\ University of Pretoria, Pretoria, 0002 South Africa \\ ${ }^{2}$ School of Animal, Plant and Environmental Sciences, University of the Witwatersrand, \\ Private Bag 3, Johannesburg, 2050 South Africa* \\ ${ }^{3}$ Department of Invertebrates, Ditsong National Museum of Natural History (formerly Transvaal Museum), \\ Pretoria, 0001 South Africa
}

Phylogenetic analysis using six outgroup and 26 ingroup taxa and 18 external adult morphological characters resulted in a paraphyletic Pegylina as composed by Lacroix (1989). To maintain the Pegylina as a monophyletic subtribe, the genus Stenopegylis Arrow, 1943 is removed from the Pegylina and placed in the Melolonthini sensu lato, pending further cladistic analyses of the Afrotropical melolonthines. Following the analyses presented here, eight character areas (antennomere number, labrum form, protarsal claw shape, protibial spur, pronotum, mesosternum and mesosternal process, body shape and sexual dimorphism) are discussed with reference to differentiating Hypopholis Erichson, 1847 syn. nov. from Pegylis Erichson, 1847. Consequently, the former is synonymized with the latter, resulting in the following new combinations: Pegylis sommeri (Burmeister, 1855) comb. nov.; P. uelensis (Burgeon, 1946) comb. nov. and P. vittata (Fåhraeus in Boheman, 1857) comb. nov. An appended checklist for the subtribe Pegylina as presently composed includes 37 species in two genera, Eupegylis Duvivier, 1892 (1 sp.) and Pegylis Erichson, 1847 (36 spp.). During outgroup selection for this analysis it became aparent that the monotypic Wernerophylla nigra Lacroix, 2001 syn. nov. is conspecific with Stenopegylis cylindrica Arrow, 1943 and consequently this synonymy is implemented here.

Key words: Melolonthinae, Adoretopsis, Eupegylis, Hypopholis, Pegylis, Pegylidius, Wernerophylla, Stenopegylis, southern Africa.

\section{INTRODUCTION}

Lacroix (1989) created the Melolonthinae tribe Pegylini to accommodate species from four genera: Eupegylis Duvivier, 1892 (1 sp.); Hypopholis Erichson, 1847 (3 spp.); Pegylis Erichson, 1847 (32 spp.); and Stenopegylis Arrow, 1943 (1 sp.) using the following morphological characters as support: (i) protibia without an apical spur; (ii) labrum elongate and bilobed; (iii) antennal club three-segmented (5-6 in Eupegylis); (iv) anterior margin of pronotum bordered by a membrane; (v) pronotum transverse; (vi) metepisternum wide (at the same level as the metepimeron); (vii) anterior femur non-subvertical; (viii) body slightly elongated, rounded or oval; (ix) sexual dimorphism limited, i.e. undeveloped.

Smith (2006), in his review of family-group names in the Scarabaeoidea, regarded the Pegylini as a subtribe (Pegylina) of the Melolonthini. Bouchard et al. (2011) followed Smith (2006), and this same rank is adopted here.

This study assesses the relationship of the genera Eupegylis, Hypopholis, Pegylis, Stenopegylis and

*Present address. E-mail: james.harrison@wits.ac.za
Wernerophylla based on a morphological phylogenetic analysis to determine or refute the monophyly of the Pegylina. It is the first of two companion papers, with the second (Harrison 2014) being a taxonomic review of the three South African species of Pegylis.

\section{MATERIAL AND METHODS}

\section{Nomenclature and specimens used}

The first mention of genera here includes authorship and date of publication, for example, Pegylis Erichson, 1847, while that for species is provided in Table 1 and Appendix 1.

Many of the specimens used in this analysis were primary or secondary museum type specimens. The advantage of this is that it allowed for wide taxon sampling within Pegylis, its related genera and synonyms, and scoring of characters from unequivocally authoritative specimens. The disadvantage is that disarticulation of these specimens to extend the character suite to include internal morphological characters is prohibited. Conse- 
quently, extending the character suite to include internal morphological characters, e.g. mouthparts would undoubtedly result in the discovery of additional characters useful for testing the monophyly of the subtribe Pegylina. However, an overriding aim of this study was to examine the generic relationship between Hypopholis and Pegylis in order to compile the much needed review of the South African 'large wattle chafers' (Harrison 2014), which this study achieves.

\section{Ingroup taxa}

Currently there are 37 species from the genera placed by Lacroix (1989) in the Pegylina: Eupegylis (1); Hypopholis (3); Pegylis (32); and Stenopegylis (1). Twenty-six of these species $(70 \%$ of the known taxa) were examined for this study (Table 1). In order to enhance monophyly, Pegylis species previously placed in genera other than indicated above are also included. Thus the monotypic Adoretopsis tenuitarsis Fairmaire, 1887 and Pegylidius mashunus Péringuey, 1904 (now both placed in Pegylis) are included as ingroup taxa. Table 1 lists all ingroup species as originally placed at the generic level to provide an indication of their nomenclatural history. This accounts for the larger number of Hypopholis species in Table 1 than currently recognized. During on-going taxonomic work on African melolonthines it became apparent that Wernerophylla nigra Lacroix, 2001 described and placed by Lacroix $(2001,2007)$ in the Pachydemini, is actually a synonym (first proposed here) of Stenopegylis cylindrica Arrow, 1943. Stenopegylis cylindrica was separately placed by Lacroix (2010) in the Pegylina and thus by default, W. nigra, is included in the analysis as S. cylindrica.

\section{Outgroup taxa}

Outgroup taxa include: (i) Asthenopholis adspersa; (ii) Brachylepis elephas; (iii) Eulepida lepidota; (iv) Psilonychus duponti; (v) Psilonychus eckloni; and (vi) Rhabdopholis albostriata. These genera were chosen because i-iii are included by Péringuey (1904) together with the following ingroup genera Hypopholis, Pegylidius and Pegylis in his group 'Leucopholides' (= Leucopholina), thus allowing for some degree of comparison between genera presently (2014) placed into two separate subtribes of the Melolonthini, i.e. Pegylina and Leucopholina. Additionally, Rhabdopholis Burmeister, 1855; Asthenopholis Brenske, 1898; and Psilonychus Burmeister, 1855 are morphologically similar to both Pegylis and Stenopegylis Arrow, 1943 and were thus also included. Rhabdopholis shares a mesosternal process and similar body shape to Hypopholis, while Asthenopholis and Psilonychus share a propygidial groove with Stenopegylis.

\section{Characters and coding}

The most informative characters from recent phylogenetic studies (Jameson 1997; Ahrens 2005; Coca-Abia 2007; Katovich 2008) of other Melolonthinae taxa were examined. Characters reused here are indicated in Table 2, although in some instances their states were modified to make them applicable to this study. During character selection, characters used in taxonomic descriptions of genera or higher taxonomic categories were specifically included. However, some of these proved difficult to code, or were invariant across the taxa used in the analysis and were thus excluded from the final data matrix (e.g. the form of the labrum). The resulting 18 morphological characters chosen to score the taxa studied here are provided in Table 2, while the character matrix is presented in Table 1.

\section{Cladistic analysis}

The matrix was analysed using a heuristic search in the WinClada (Ver. 1.00.08) interface (Nixon 2002). From WinClada the data analyses were undertaken in Nona (Goloboff 1997) using these parameter settings: hold 10000 (hold a maximum of 10000 trees in memory); mult ${ }^{*} 100$ (with 100 randomized replications); hold/10 (starting each replication of branch-swapping with 10 trees in memory); 0 = time ('pseudo-random number generator based on the time in order to select the sequence of addition of the replications' Hardy et al. (2003)). With the following search strategy mult* max $^{*}$ (multiple tree bisection-reconnection (TBR) + TBR), in an unconstrained search, as suggested by Hardy et al. (2003) for an initial search on data sets with less than 120 taxa. The characters were treated as non-additive and with equal weights. Characters were polarized by outgroups (Nixon \& Carpenter 1993), represented herein by Asthenopholis (used for rooting), Brachylepis, Eulepida, Rhabdopholis, Psilonychus and including other genera of Pegylina as more closely-related outgroups, i.e. Eupegylis and Stenopegylis. WinClada was also used to view character states and to calculate a Nelsen strict consensus tree (SCT) and bootstrap and jack-knife support values for the nodes on the resulting SCT. 
Table 1. Character states of the six outgroup and 26 ingroup taxa used in the analysis. Character descriptions provided in Table 2. '?' = unknown character state/s.

\begin{tabular}{|c|c|c|c|}
\hline Characters & & 1 & \\
\hline \multicolumn{4}{|l|}{ Outgroup taxa } \\
\hline Asthenopholis adspersa & (Boheman, 1857) & 0000002102 & 01101201 \\
\hline Brachylepis elephas & (Gerstaecker, 1867) & 0000000122 & 01100202 \\
\hline Eulepida lepidota & (Klug, 1855) & 0200002120 & 01100201 \\
\hline Psilonychus duponti & Burmeister, 1855 & 2300002122 & 00001100 \\
\hline Psilonychus eckloni & Burmeister, 1855 & 2200002121 & 00001100 \\
\hline $\begin{array}{l}\text { Rhabdopholis albostriata } \\
\text { Ingroup taxa }\end{array}$ & \multicolumn{2}{|c|}{ Ingroup taxa } & 02000100 \\
\hline Adoretopsis tenuitarsis & Fairmaire, 1887 & 1100011003 & 11110200 \\
\hline Eupegylis confusa & Duvivier, 1892 & 1100120100 & 11000303 \\
\hline Hypopholis conspurcata & Gerstaecker, 1867 & 1200011003 & 11110112 \\
\hline Hypopholis sommeri & Burmeister, 1855 & 1110011003 & 02010100 \\
\hline Hypopholis uelensis & Burgeon, 1946 & 1200011003 & 02010200 \\
\hline Hypopholis vittata & Fåhraeus in Boheman, 1857 & 1110010003 & 01010100 \\
\hline Pegylidius mashunus & Péringuey, 1904 & 1200010003 & 10110201 \\
\hline Pegylis angolensis & Moser, 1915 & $11 ? 0010000$ & 00110202 \\
\hline Pegylis bennigseni & Brenske, 1898 & 1200010003 & 10110201 \\
\hline Pegylis burgeoni & Decelle, 1968 & 1100110003 & 20110001 \\
\hline Pegylis ertli & Moser, 1919 & 1210010003 & 21110115 \\
\hline Pegylis gestroi & Brenske, 1895 & 1200010003 & 20110115 \\
\hline Pegylis giraudetae & Decelle, 1968 & 1100110013 & 11110200 \\
\hline Pegylis hauseri & Brenske, 1898 & 1000010003 & 20110100 \\
\hline Pegylis kenyensis & Decelle, 1968 & 1201010003 & 20110106 \\
\hline Pegylis lindiania & Moser, 1919 & 1110010003 & 11110200 \\
\hline Pegylis maculipennis & van Lansberge, 1889 & 1201010003 & 10110100 \\
\hline Pegylis microchaeta & Moser, 1919 & 1100011003 & 21110200 \\
\hline Pegylis morio & Blanchard, 1851 & 1201010000 & 00110106 \\
\hline Pegylis neumanni & Kolbe, 1894 & 1200010003 & 10110200 \\
\hline Pegylis pilosa & Lacroix, 2008b & 1000010010 & 00110101 \\
\hline Pegylis pondoensis & Arrow, 1943 & 1110011003 & 01010000 \\
\hline Pegylis rufolineata & Kolbe, 1894 & 1200010003 & 21110115 \\
\hline Pegylis rufomaculatus & Linell, 1896 & 1210010003 & 21110115 \\
\hline Pegylis vestita & Brenske, 1895 & 1201010013 & 20110200 \\
\hline Stenopegylis cylindrica & Arrow, 1943 & 1100003142 & 00001200 \\
\hline
\end{tabular}

\section{RESULTS AND DISCUSSION}

The parsimony analysis produced 46 equally most parsimonious (EMP) trees, with a length of 94 steps, and a CI $=0.39$ and $\mathrm{RI}=0.71$. A Nelsen strict consensus tree (SCT) was calculated from these 46 trees. The SCT (Fig. 1) has a length of 144 steps, with a $\mathrm{CI}=0.47$ and $\mathrm{RI}=0.47$. Bootstrap (Fig. 2) and jack-knife (Fig. 3) support values were calculated for the nodes of the SCT. The number of steps, ci and ri for each character are included in Table 2. The checklist in Appendix 1 lists all species of Pegylina including the generic changes resulting from this analysis.

\section{Monophyly of the subtribe Pegylina Lacroix, 1989}

Node: (((Asthenopholis adspersa) (Brachylepis elephas + Eulepida lepidota + Rhabdopholis albostriata + Stenopegylis cylindrica) (Psilonychus eckloni + Psilonychus duponti)) $((($ Eupegylis confusa + Pegylis angolensis + Pegylis bennigseni + Hypopholis conspurcata + Pegylis giraudetae + Pegylis lindiania + Pegylidius mashunus + Pegylis 
Table 2. Adult morphological characters (scored for both sexes) used in the phylogenetic analysis of genera placed by Lacroix (1989) in the subtribe Pegylina. For each character, the number of steps in the tree (S), consistency index (ci) and the retention index (ri) are provided, based on the parsimony analysis performed in WinClada. References within the table indicate character sources, prior to these being modified and used in this analysis.

1) Protibial spur: (0) present; (1) absent; (2) residual. $S=4 ; \mathrm{ci}=50$; ri $=50$.

2) Number of protibial teeth: (0) three; (1) two (third reduced); (2) two; (3) one (second reduced). $S=15 ; \mathrm{ci}=20$; $\mathrm{ri}=29$.

3) Protarsal claws (in males): (0) symmetrical; (1) asymmetrical. $S=5$; $c i=20$; $r i=20$.

4) Number of antennomeres: (0) nine or ten; (1) eight or less. $S=2$; ci = 50; ri = 66. (Ahrens 2005: character 5).

5) Eyes: (0) normally convex; (1) strongly convex; (2) with dorsal light patch. $\mathrm{S}=3$; $\mathrm{ci}=33$; ri $=0$.

6) Anterior margin of pronotum bordered by a membrane: (0) absent; (1) present; (2) present, but slight. $S=2$; ci $=100$; ri $=100$.

7) Anterior margin (dorsal section) of pronotum: (0) defined by a groove (marginal bead) continuous from side to side; (1) defined by a groove only on each side towards the angles; (2) groove absent; (3) notched on each side towards the angle. $\mathrm{S}=11 ; \mathrm{ci}=27$; $\mathrm{ri}=50$.

8) Lateral margins of pronotum: (0) smooth; (1) finely serrated; (2) coarsely serrated. $\mathrm{S}=3$; $\mathrm{ci}=33$; $\mathrm{ri}=66$. (Coca-Abia 2007: character 16).

9) Pronotum surface: (0) uniformly clothed with short fine setae; (1) uniformly clothed with long fine setae; (2) scaliferous; (3) no or few setae / scales; (4) uniformly clothed with short and long fine setae. S = 9; $\mathrm{ci}=44 ; \mathrm{ri}=61$.

10) Colour of elytra: (0) brown; (1) russet; (2) black; (3) bi-coloured. $S=16$; $c i=18$; ri = 31.

11) Mottling on elytra; (0) absent; (1) slightly mottled; (2) strongly mottled. $\mathrm{S}=13$; $\mathrm{ci}=15$; $\mathrm{ri}=47$.

12) Mesosternum (as a mesosternal keel): (0) not produced; (1) weakly produced, not surpassing the base of mesocoxae; (2) produced anteriorly beyond base of the mesocoxae. $\mathrm{S}=14 ; \mathrm{ci}=14 ; \mathrm{ri}=25$. (Jameson 1997: character 110).

13) Mesosternum: (0) without rim; (1) with rim. $S=8$; $c i=12$; ri = 12.

14) Median depression on abdominal sternites (of male): (0) absent; (1) present. $S=2$; $\mathrm{ci}=50$; $\mathrm{ri}=85$.

15) Propygidial groove: (0) absent; (1) present. $S=0$. Uninformative.

16) Adeagus lateral profile: (0) straight; (1) smoothly curved; (2) sharply angulate; (3) laterally produced. $S=13$; ci $=23$; ri $=33$.

17) Adeagus symmetry: (0) symmetrical; (1) asymmetrical. $S=3$; ci $=33$; ri $=50$.

18) Adeagus symmetry and complexity: (0) symmetrical and simple (no protuberances); (1) symmetrical and complex (one set of protuberances); (2) symmetrical and complex (two or more sets of protuberances); (3) symmetrical and complex (including setae) (4) asymmetrical and simple (one set of protuberances); (5) asymmetrical and complex (two or more sets of protuberances); (6) symmetrical with a three-bladed internal section. $\mathrm{S}=21$; $\mathrm{ci}=28$; $\mathrm{ri}=63$.

microchaeta + Pegylis neumanni + Pegylis pilosa + Pegylis pondoensis + Hypopholis sommeri + Adoretopsis tenuitarsis + Hypopholis uelensis + Hypopholis vittata) (Pegylis maculipennis + Pegylis vestita $))($ Pegylis burgeoni + Pegylis hauseri $))((($ Pegylis gestroi + Pegylis rufolineata $)$ $($ Pegylis ertli + Pegylis rufomaculatus $))($ Pegylis kenyensis + Pegylis morio)))) = Fig. 1 .

As currently composed, the Pegylina is paraphyletic (Fig. 1) due to Stenopegylis (=Wernerophylla), a monotypic genus, occurring outside of the 'Pegylina clade'. However, the removal of Stenopegylis from the Pegylina, based on the absence of a membrane on its anterior pronotal margin (an apparent synapomorphy for the Pegylina), returns the Pegylina to a monophyletic group based on the following synapomorphies, with 'character: state' indicated in brackets: anterior margin of pronotum bordered by a membrane (C6:S1); bi-coloured elytra (C10:S3); slight mottling on elytra (C11:S1); and median depression on abdominal sternites (of male) present (C14:S1).

Support values for the Pegylina clade ((((Eupegylis confusa ... Pegylis morio)))) are $65 \%$ bootstrap support (Fig. 2) and $74 \%$ jack-knife (Fig. 3).

Consequently, Stenopegylis cylindrica Arrow, 1943 is transferred to the Melolonthini sensu lato pending further analyses of relationships among African 


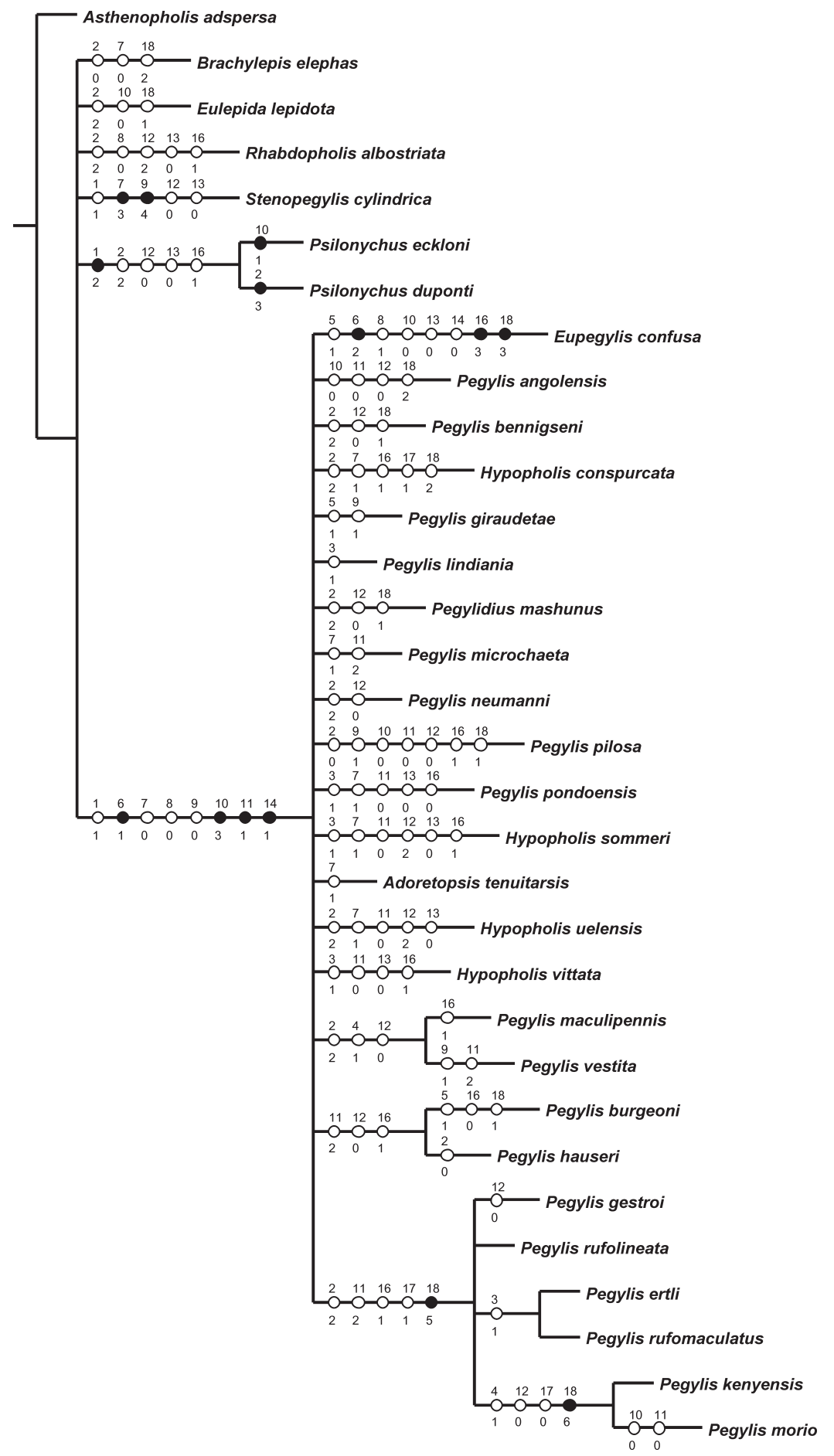

Fig. 1. Strict consensus tree for the subtribe Pegylina and outgroup taxa included in the analysis, using Asthenopholis adspersa to root the tree. Open circles (0) represent homoplasious character state changes. Filled circles ( $(\mathbf{0})$ represent non-homoplasious character state changes. Character number above each circle; character state below each circle. 


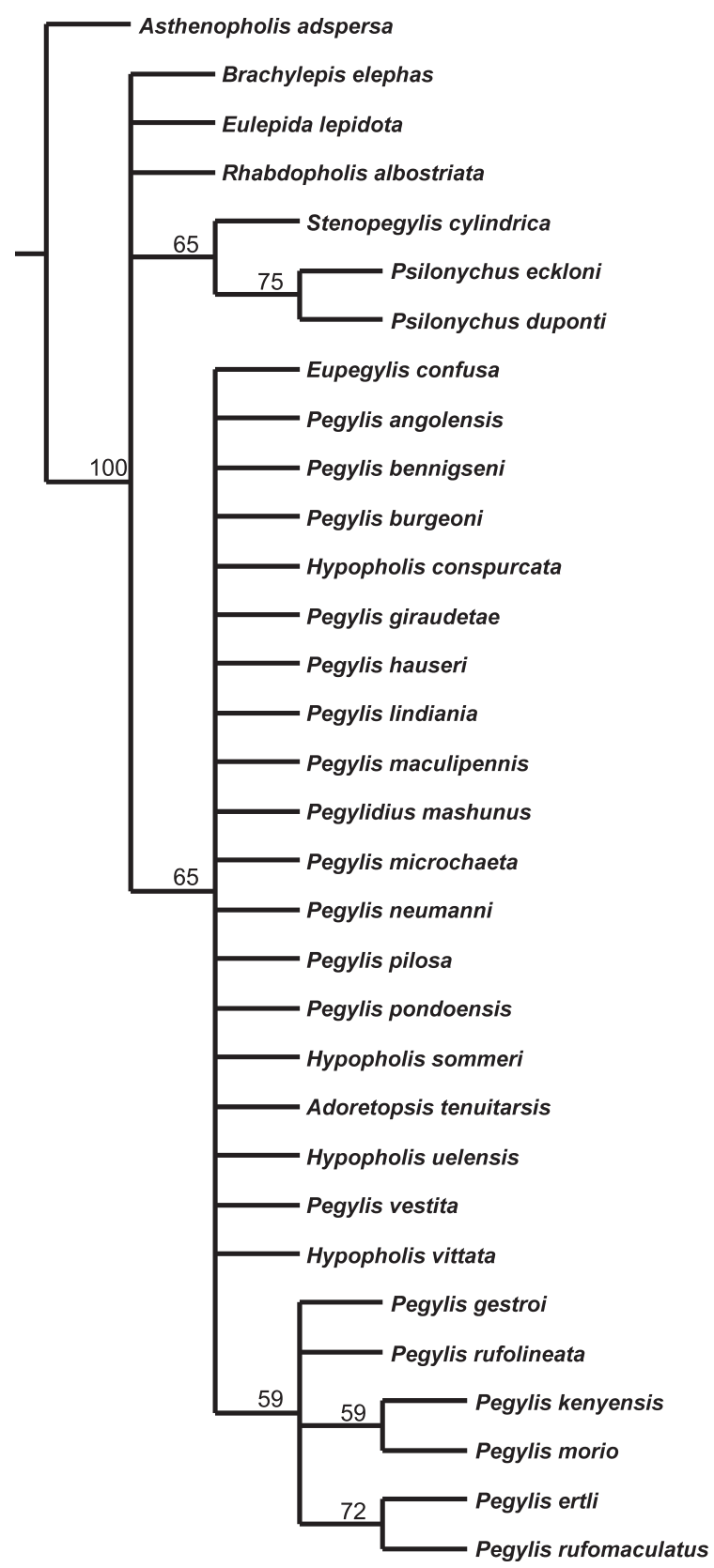

Fig. 2. SCT with bootstrap values indicated on supported nodes.

genera of Melolonthinae. Arrow (1943: 783-784) wrote the following after having described this monotypic genus:

Although differing very greatly from Pegylis in its external appearance, the insect for which this genus is proposed is nearly related to it and shares with it the peculiar sexual difference in claw-structure as well as the no less peculiar absence of the normal tibial spur at the base of the front tarsus. It differs especially in its narrow cylindrical shape, instead of the broadly ovate form characteristic of Pegylis, the small head, with its prominent clypeus, the short diverging lobes of the labrum, and the existence of a longitudinal groove upon the propygidium, similar to that I described in 1902 [Arrow 1902] as distin- 


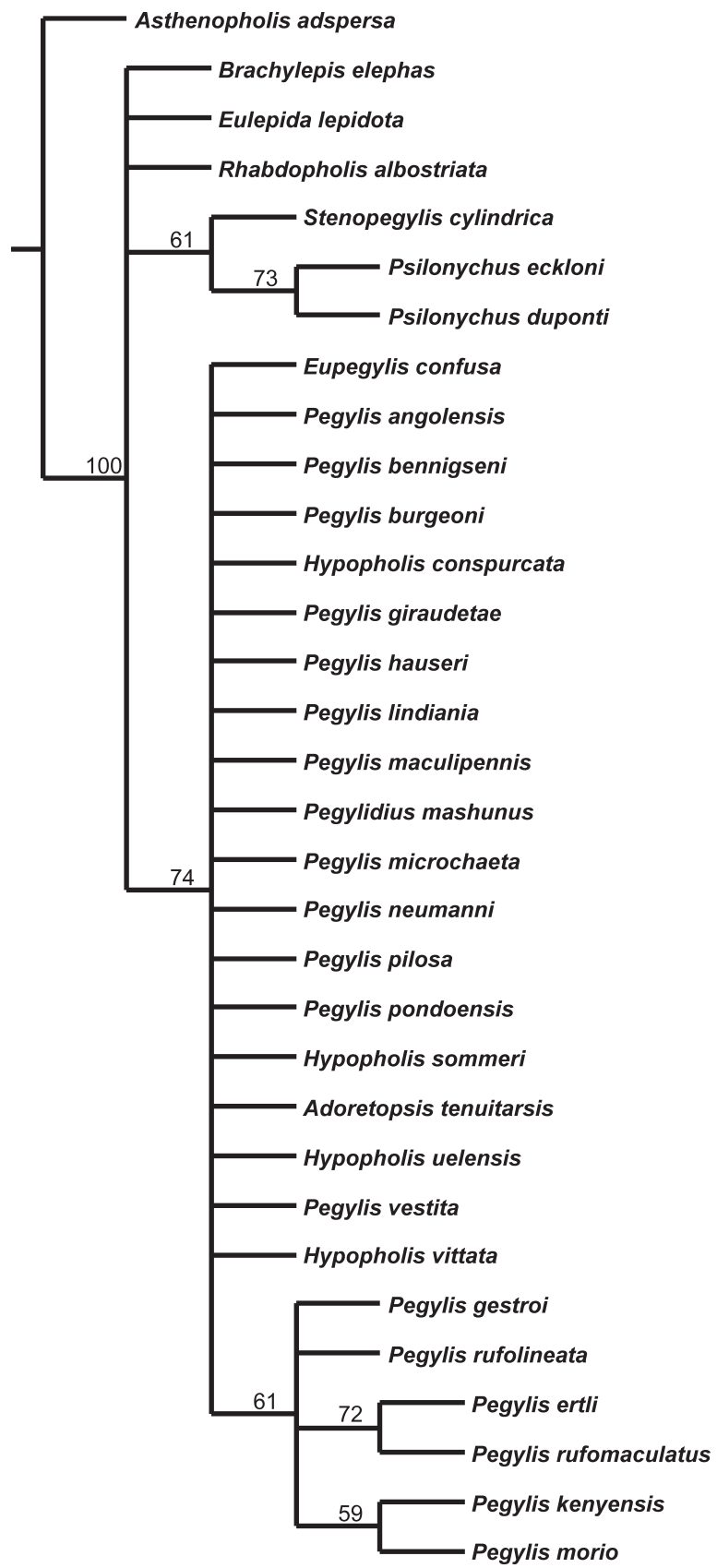

Fig. 3. SCT with jack-knife values on supported nodes.

guishing the genus Asthenopholis, to which Stenopegylis has some superficial resemblance, although clothed with hair instead of scales.

Harrison (2009) provided a revision of Asthenopholis including a discussion of the occurrence of a grooved propygidium within various scarab taxa.

\section{Monophyly of Adoretopsis, Hypopholis and Pegylidius}

Node: (((Eupegylis confusa + Pegylis angolensis + Pegylis bennigseni + Hypopholis conspurcata + Pegylis giraudetae + Pegylis lindiania + Pegylidius mashunus + Pegylis microchaeta + Pegylis neumanni + Pegylis pilosa + Pegylis pondoensis + Hypopholis sommeri + Adoretopsis 
Table 3. Morphological features used by Erichson (1847) to differentiate Hypopholis from Pegylis.

Hypopholis

(i) Antennae 10-segmented with 3-segmented club

(ii) Labrum large, deeply split/incised*

(iii) Pronotum posterior closely adjacent to elytral base

(iv) Mesosternum with a long process
Pegylis

Antennae 8-segmented with 3-segmented club Labrum as in Hypopholis*

Pronotum small and not closely adjacent to elytra (i.e. gap in between)

Mesosternum simple

${ }^{\star}$ Character (ii) does not differentiate between Hypopholis and Pegylis, and it is thus an invalid character at the generic level. However, it is included here as done by Erichson (1847) for discussion purposes.

tenuitarsis + Hypopholis uelensis + Hypopholis vittata (Pegylis maculipennis + Pegylis vestita) $)($ Pegylis burgeoni + Pegylis hauseri $))((($ Pegylis gestroi + Pegylis rufolineata $)$ (Pegylis ertli + Pegylis rufomaculatus $))($ Pegylis kenyensis + Pegylis morio)))) = Pegylina clade

Four synapomorphies (as listed above and indicated (•) in Fig. 1) support the monophyly of the Pegylina clade. This analysis thus supports Arrow's (1943) previous synonymy of Pegylidius with Pegylis, the more recent synonymy of Adoretopsis with Pegylis (Lacroix 2010). Results provide evidence that Hypopholis is synonymous with Pegylis, and that Pegylis and Eupegylis are closely related (Fig. 1).

\section{Validity of Eupegylis and Pegylis as genera}

Node: $(((($ Eupegylis confusa ... Pegylis morio $))))$ = Pegylina clade

Three synapomorphies support the validity of the genus Eupegylis, i.e. anterior margin of pronotum bordered by a slight membrane (C6:S2; $\mathrm{S}=2 ; \mathrm{ci}=100 ; \mathrm{ri}=100)$; adeagus laterally produced in profile (C16:S3; $\mathrm{S}=13$; $\mathrm{ci}=23$; $\mathrm{ri}=33)$; adeagus symmetrical and complex (including setae) (C18:S3; $\mathrm{S}=21$; ci $=28$; ri = 63). Consequently, Eupegylis is retained as a valid genus due to the support of these synapomorphies (Fig. 1).

Four synapomorphies support the validity of the genus Pegylis, i.e. anterior margin of pronotum bordered by a membrane (C6:S1; S = 2; ci = 100; ri = 100); elytra bi-coloured (C10:S3; S = 16; ci = 18; ri = 31); elytra slightly mottled (C11:S1; $\mathrm{S}=13$; $\mathrm{ci}=15$; ri $=47)$; median depression on abdominal sternites (of male) present (C14:S1; $\mathrm{S}=2$; ci $=50$; $\mathrm{ri}=85)$. Of these characters, the anterior margin of the pronotum bordered by a membrane provides strong support ( $\mathrm{ci}=100$; ri $=100$ ) for the Pegylina clade and a synapomorphy for all species of Pegylis, with the other Pegylina genus, Eupegylis, also having this membrane (but being less developed).

\section{An assessment of Erichson's (1847) charac- ters used to differentiate Hypopholis from Pegylis and an evaluation of the characters used by Lacroix (1989) to define the subtribe Pegylina}

Node: ((((Eupegylis confusa ... Pegylis morio $))))$ = Pegylina clade

Erichson (1847) described both Hypopholis and Pegylis listing the characters provided in Table 3 to differentiate between them. To represent these genera he placed two South African species in Hypopholis, i.e. Leucopholis sommeri Dejean ${ }^{1}$ and Leucopholis vittata Boheman ${ }^{2}$, and one from 'Sennaar' in the Sudan in Pegylis, i.e. Melolontha morio Kolbe (in litt.).

Here follows a discussion of characters used by Erichson (1847) and previous authors to differentiate Hypopholis from Pegylis in order to reassess their validity as generic characters. Additionally, the characters used by Lacroix (1989) to define the subtribe Pegylina are included in the discussion.

\section{(i) Antennae (character 4)}

Erichson (1847) used 'antennae 10-segmented with a 3-segmented club' versus 'antennae 8-segmented with a 3-segmented club' to distinguish Hypopholis from Pegylis. In his generic description of Pegylidius Péringuey (1904) noted the antennal number as 'antennae 10-jointed'. In 1943, Arrow commented that:

\section{In P. mashunus and P. pondoensis the antennae have all the joints of the footstalk separate, while in most of the species the males have them more or less fused together, but I consider this also useless for a generic separation, as applying to one sex only.}

Consequently, Arrow (1943) synonymized Pegylidius with Pegylis mentioning that the num-

${ }^{1}$ Pegylis sommeri (Burmeister, 1855) comb. $\mathrm{n}$.

${ }^{2}$ Pegylis vittata (Fåhraeus in Boheman, 1857) comb. $n$.

${ }^{3}$ Pegylis morio Blanchard, 1850. 
ber of antennal segments is an invalid generic character in this particular instance. In his characterization of the Pegylini Lacroix (1989) included a three-segmented antennal club for Hypopholis, Pegylis and Stenopegylis, but Eupegylis with a 5-6 segmented antennal club.

The number of antennal segments has historically been used as a generic character in various phytophagous scarabs. However, a recent study (Ahrens \& Vogler 2008) has shown that it is too variable to be a reliable generic character. In the analysis, the number of antennomeres (C4) was coded following Ahrens (2005) using only two states, i.e. (0) nine or 10 antennomeres and (1) eight or fewer antennomeres. Thus, character 4 is two steps in length on the SCT (Fig. 1), with a ci $=50$ and $\mathrm{ri}=66$. The second state is found only supporting the following subclades (Pegylis maculipennis + Pegylis vestita) and (Pegylis kenyensis + Pegylis morio) on the SCT. Harrison (2014) provides clear illustrations in Figs 13-15 of the 10-segmented antennae in specimens of the following species (P. sommeri, $P$. pondoensis and $P$. vittata) examined here. Thus, although it is quite possible to have individuals or even populations with a reduced number of antennal segments, this character is not regarded here as valid to separate Pegylidius from Pegylis, nor Hypopholis from Pegylis, at the generic level.

\section{(ii) Labrum (uninformative character)}

Erichson (1847) described the labrum of Hypopholis as '... large, deeply split/incised', while that of Pegylis as 'labrum as in Hypopholis', suggesting no morphological difference between these genera based on the labrum. Lacroix (1989) described the labrum of the subtribe Pegylina taxa to be elongate and bilobed.

During selection of characters to code for the analysis the labrum of all available taxa (37 species; $n=5$ ) were examined and other than morphological differences at species level, i.e. varying depths of the incision possibly related to intraspecific diets, no characters differentiating at the generic level were observed, and thus the labrum was excluded from the analysis when the data matrix was 'mopped' in WinClada to remove uninformative characters. Consequently, the shape of the labrum is also regarded here as an invalid generic character to differentiate Hypopholis from Pegylis.

\section{(iii) Protarsal claws (character 3)}

Gerstaecker (1867) appears to be the earliest author to comment on the protarsal claw morphology of Hypopholis and Pegylis and noted the difference between $H$. sommeri and $H$. vittata as:

...the shape of the tarsal claws ... in H. sommeri are in the middle very strongly dentate, [while] in $H$. vittata the posterior tibial claws are simple; the protibial claws with a simple inner [claw] and split external [claw].

Gerstaecker (1873) added to this by noting the differing tarsal claw morphology between $H$. conspurcata, $H$. sommeri and $H$. vittata as:

It is intriguing that [of] the three species that are known to date, all show distinctly/unusually shaped claws: (i) all claws apically deeply split: $H$. conspurcata; (ii) all claws medially strongly dentate [toothed]: H. sommeri; (iii) meso- and metatarsal claws simple [unmodified]; protarsal inner claw simple, outer claw split: $H$. vittata...

Note that of the three species discussed above, one is subsequently transferred to Pegylis and the other two retained in Hypopholis (see Appendix 1).

In the analysis, male protarsal claws were scored as symmetrical (0) or asymmetrical (1), and this character failed to contribute differentiation at the generic level among the taxa of Pegylina included in the analysis $(\mathrm{C} 3 ; \mathrm{S}=5 ; \mathrm{ci}=20 ; \mathrm{ri}=20)$. However, it did provide interspecific support for these species: Pegylis lindiania, P. pondoensis, Hypopholis sommeri, and the sub-clade P. ertli + P. rufomaculatus (Fig. 1).

Arrow (1901) discussed the undesirability of using sexually dimorphic characters on which to base genera, and provided examples from the Scarabaeidae: Rutelinae to illustrate this. Péringuey (1904) described Pegylidius as a new genus for a Zimbabwean species (P. mashunus) and remarked that, 'plainly [it is] allied to Hypopholis, but differing mainly by the structure of the claws and simple mesosternum.' Arrow (1943) in his discussion of Pegylis and Pegylidius concluded that, 'It is evident for generic purposes the claws are useless and I therefore regard Pegylidius as a synonym of Pegylis'. Having examined most of the described species of Pegylis (see * in Appendix 1), it is apparent that the protarsal claws are sexually dimorphic, inter- and intraspecifically variable and thus this character is also regarded here, for these taxa, as invalid on which to base genera.

\section{(iv) Absence of a protibial spur (character 1)}

Kolbe (1894) in his Synopsis of the Genera of the Leucopholines from the Ethiopian Region differentiated Pegylis and Hypopholis from five other genera 
which he described as new by 'protibia without spurs'. I am not aware of any earlier authors specifically noting this character in these genera.

The complete absence of a protibial spur in both sexes is a key character used by Lacroix (1989) to define the subtribe Pegylina. However, this character (C1:S1) is not unique to the Pegylina. Examples of other melolonthine genera that lack, or have reduced, protibial spurs include the following ${ }^{4}$ : the monotypic Oncerus floralis LeConte, 1856 , which is one of two monotypic genera in the tribe Oncerini LeConte (A.V. Evans, pers. comm.); the tribe Podolasiini Howden, 1997 comprising Podolasia Harold and Podostena Howden (A.V. Evans, pers. comm.) are both without a protarsal spur, as illustrated in Howden (1954: figs 1-5); Chaunocolus Saylor (monotypic) and Chnaunanthus Burmeister (comprising about three species) (formerly Chasmatopterini (Evans 2003)), recently placed by Evans \& Smith (2009) in genera 'incertae sedis'), also see Baraud \& Branco (1990) and Branco (2004) for discussion on Chasmatopterus Dejean; Ceratogonia Kolbe (monotypic) from the tribe Diplotaxini Burmeister (Bezděk 2004a,b). In addition, many New World Macrodactylini do not possess a protibial spur (Smith 2008), examples include, Ampliodactylus Smith, Pusiodactylus Smith, Macrodactylus Dejean and some Pristerophora Harold. This character is variable within the Macrodactylini (A.B.T. Smith, pers. comm.) and Katovich (2008) provided a partial list of some taxa where this character is variably expressed (see Katovich's character 54 (pp. 10, 76)). Within the Melolonthini: Rhizotrogina, Brachyllus Brenske is a genus lacking a protibial spur (Keith 2003, 2005, 2007). Some Eulasia (Rudeulasia) Baraud (Glaphyridae) lack the spur at least in males, whereas most species have one, but D. Keith (pers. comm.) found that in these species it is more often vestigial rather than completely absent. Finally, members of the scarab subfamily Aclopinae Blanchard, have no protibial spurs (F.C. Ocampo, pers. comm.).

Character 1 , state 1 (= protibial spur absent) occurs as a homoplasious character state change for Stenopegylis cylindrica and for the Pegylina clade (Fig. 1), with character 1 , state 2 (= protibial spur residual) as a non-homoplasious character state change (synapomorphy) for the genus Psilonychus (Fig. 1).

As indicated by the analysis and discussion

${ }^{4}$ These examples were provided by Scarab-L list server members, and consequently (pers. comm.) is used extensively here to acknowledge their source. above, the complete absence of protibial spurs in both sexes of Pegylis is a homoplasious character state change for Pegylis and Eupegylis, while being a synapomorphy for the two species of Psilonychus included in this analysis.

\section{(v) Pronotum (characters 6, 7, 8 \& 9)}

Erichson (1847) used 'posterior pronotum closely adjacent to elytral base' for Hypopholis versus 'pronotum small and not closely adjacent to elytra' [separated by a gap] for Pegylis. The relative position of the posterior section of the pronotum in relation to the elytral base is entirely dependent on how the specimen being examined died, was mounted and dried. This is because in live specimens there is ample articulation between these two body sections. Thus, I do not regard this character as justifiable to separate Hypopholis from Pegylis at the generic level.

Character 6. Anterior margin of pronotum bordered by a membrane: (0) absent; (1) present; (2) present, but slight. $\mathrm{S}=2$; $\mathrm{ci}=100$; ri $=100$. Character 6 , state 2 represents a non-homoplasious character state change for Eupegylis confusa (Fig. 1). Lacroix (1989) included the anterior margin of the pronotum bordered by a membrane as a defining feature for the Pegylina. Character 6, state 1 represents a non-homoplasious character state change (synapomorphy) for the Pegylina clade.

Character 7. Anterior margin (dorsal section) of pronotum: (0) defined by a groove continuous from side to side; (1) defined by a groove only on each side towards the angles; (2) groove absent; (3) notched on each side towards the angle. $S=11$; $\mathrm{ci}=27 ; \mathrm{ri}=50$. Character 7 , state 0 represents a homoplasious character state change for Brachylepis elephas and the Pegylina clade. Character 7, state 1 represents a homoplasious character state change for Hypopholis conspurcata, Pegylis microchaeta, P. pondoensis, H. sommeri, Adoretopsis tenuitarsis and H. uelensis. Character 7, state 3 represents a nonhomoplasious Character state change for Stenopegylis cylindrica.

Character 8. Lateral margin of pronotum: (0) smooth; (1) finely serrated; (2) coarsely serrated. $\mathrm{S}=3$; $\mathrm{ci}=33 ; \mathrm{ri}=66$. Character 8 , state 0 represent homoplasious character state changes for Rhabdopholis albostriata and the Pegylina clade in the analysis (Fig. 1). Character 8, state 1 represent homoplasious character state changes for Eupegylis confusa.

Character 9. Pronotum surface: (0) uniformly 
clothed with short fine setae; (1) uniformly clothed with long fine setae; (2) scaliferous; (3) no or few setae/scales; (4) uniformly clothed with short and long fine setae. $S=9$; $\mathrm{ci}=44$; $\mathrm{ri}=61$. Character 9 , state 0 represents a homoplasious character state change for the Pegylina clade. Character 9, state 1 represents a homoplasious character state change for Pegylis giraudetae, $P$. pilosa and P. vestita. Character 9 , state 4 represents a non-homoplasious character state change for Stenopegylis cylindrica.

\section{(vi) Mesosternum process (character 12) and mesosternum (character 13)}

Erichson (1847) indicated that Hypopholis has a mesosternum with a long process, as opposed to a simple mesosternum in Pegylis. The presence or absence of a mesosternal process appears to occur at specific rather than at generic level within the Pegylina, as species separated from Hypopholis based on this character alone, are equally placed into Pegylis using other characters. The presence of a mesosternal process (keel or peg-like projection) is an obvious character used to separate Hypopholis from Pegylis, and historically any species with such a process was placed in Hypopholis and those without it into Pegylis. A brief overview of the presence of a mesosternal process in some other scarab taxa is provided below.

Melolonthinae and Rutelinae: in combination with other characters, the presence/lack of mesosternal process was/is used to differentiate the following generic couples: Melolontha Fabricius from Hoplosternus Blanchard (now regarded as a synonym of Melolontha (see Bunalski 2002)), Leucopholis Blanchard from Lepidiota Hope (D. Keith, pers. comm.), and Mimela Kirby from Anomala Samouelle (Kim 1996). In the endemic Australian genus Sciton Blackburn (Melolonthinae: Liparetrini), almost all species belonging to this genus possess a mesosternal projection, ranging from a long setose peg to a short peg, others with a longitudinal keel of varying height to none at all (A. Szitó, pers. comm.). Within Sciton, A. Szitó (pers. comm.; presently revising this genus) does not consider it to be a generic character. A. Bezděk (pers. comm.) is not aware of a mesosternal keel in any diplotaxine species, thus it appears to be absent in the Diplotaxini. All known species of the following genera (Proagosternus Blanchard; Pseudodicrania Gutiérrez (Evans 2003); Rhabdopholis Burmeister (Harrison 2004) have some degree of a mesosternal keel.
Many rutelines have a well-developed mesometasternal process which is suspected to be for flight muscle attachment, as strong fliers often have a well-developed process, but specimens would need to be dissected to show that this is the case (M.L. Jameson, pers. comm.). For example, a mesosternal process is observed in several species of Parastasia (Kuijten 1992). In Parastasia, the presence of the process is not a generic character, but does discriminate a few species from others within the genus (A. Bezděk, pers. comm.).

Cetoniinae: within the cetoniines many genera and species have a mesosternal process (see Holm \& Marais 1992). Several Ethiopian Trichiinae (sensu Krikken 1984) genera bear a noticeable mesosternal projection (E. Ricchiardi, pers. comm.). Within a wide selection of Cremastocheilini examined by G. Mynhardt during research for Mynhardt \& Wenzel (2010), the presence of a mesosternal projection was variably apparent, but always present (Mynhardt, pers. comm.).

Dynastinae: many genera (or parts of genera) of dynastines have a prosternal peg, the shape of which is used as a character in some of Endrödi's (1985) keys, for example Peltonotus Burmeister (Jameson \& Wada 2004, 2009).

Scarabaeinae: the presence of a well-developed spiniform prosternal projection is one of the defining characters of the genus Oxysternon (Phanaeini) (Edmonds \& Zídek 2004), whereas this same feature is less well developed in a related genus Phanaeus (Philips et al. 2004; Price 2007, 2009).

Phaenomeridinae: a mesosternal projection is found in the genus Phaenomeris Hope (Phaenomerinae) (A. Ballerio, pers. comm.).

B. Warner's (pers. comm.) response to the scarab list provides an informative summary of a pro/ mesosternal projection, and thus I include it here.

\footnotetext{
Absent in many smaller scarabs. Actually, they are commonplace in many scarabaeoid groups, and fairly common in Coleoptera. No doubt there have been many independent evolutions of such pegs, as they are the simple answer to stiffen prothoracic/mesothoracic flexion, or head (mentum in cremastocheilines)/prothoracic flexion, and act like a 'door stop.' The standard locations are anterior to procoxae, posterior to procoxae, and protruding from the mesometasternal junction. As for use as a generic character, Mimela vs. Anomala (and relatives) is an example. However, in many genera pegs may range from absent to large. Such pegs are generally not used at higher taxonomic categories given frequent parallelisms and variable expression.
} 
Character 12. Mesosternum (as a mesosternal keel): (0) not produced; (1) weakly produced, not surpassing the base of mesocoxae; (2) produced anteriorly beyond base of the mesocoxae. $S=14$; $\mathrm{ci}=14$; ri = 25 (Jameson 1997: Char 110). Character 12 , state 0 represents a homoplasious character state change for Stenopegylis cylindrica, Psilonychus eckloni + Psilonychus duponti, Pegylis angolensis, P. bennigseni, Pegylidius mashunus, P. neumanni, P. pilosa, P. maculipennis + P. vestita, P. burgeoni $+P$. hauseri, P. gestroi and P. kenyensis + P. morio. Character 12 , state 2 represents a homoplasious character state change for Rhabdopholis albostriata, Hypopholis sommeri and H. uelensis.

Character 13. Mesosternum: (0) without rim; (1) with rim. $S=8 ; \mathrm{ci}=12 ; \mathrm{ri}=12$. Character 13 , state 0 represents a homoplasious character state change for Rhabdopholis albostriata, Stenopegylis cylindrica, Psilonychus duponti + Psilonychus eckloni, Eupegylis confusa, Pegylis pondoensis, Hypopholis sommeri, Hypopholis uelensis and Hypopholis vittata.

Consequently, mesosternal characters and especially the presence of a mesosternal keel/process is not a homology (synapomorphy) for Hypopholis or any other genera included in this analysis. Therefore, the presence or absence of a mesosternal process is regarded as an invalid character to base genera on within the Pegylina.

\section{(vii) Body shape (too subjective to score)}

Lacroix (1989) includes the body shape (body slightly elongated, rounded or oval) in his description of the Pegylina. It is true that all genera of Pegylina share this 'streamlined' body shape, but so do many other genera of melolonthines, for example, Eulepida, Lepidiota, Leucopholis and Rhabdopholis. Consequently, it is regarded as an invalid character for tribal/subtribal level discrimination, but is obviously valid as part of a habitus description for taxa within a respective taxonomic group.

\section{(viii) Sexual dimorphism (characters 3, 14)}

For the Pegylini Lacroix (1989) defines sexual dimorphism as limited or undeveloped. Within the Scarabaeoidea sexual dimorphism varies from quite marked to almost indistinguishable. Large horned Cetoniinae, Dynastinae and Scarabaeinae males can differ so much from their conspecific females that they can and have been regarded as different species. However, once associated via locality data or if collected in copula, the sexes of conspecifics are easily separated macroscopically. Minor males of the above taxa merge into the female body form, and are thus our exception to this rule-of-thumb. However, experienced taxonomists quickly learn to differentiate the sexes of the groups on which they work. Male Pegylina have a distinctive median-lateral groove on their ventral sternites, slightly longer antennal clubs, and different tarsal claws compared to females.

Apart from the form of the male genitalia two additional gender-related characters were included in the analysis, i.e. C3 and C14.

Character 3. Protarsal claws (in males): (0) symmetrical; (1) asymmetrical. $\mathrm{S}=5$; $\mathrm{ci}=20$; $\mathrm{ri}=20$. The morphology of the male protarsal claws is covered under point (iii) above and only provided interspecific support.

Character 14. Median depression on abdominal sternites (of male): (0) absent; (1) present. $S=2$; $\mathrm{ci}=50 ; \mathrm{ri}=85$. Character 14 , state 0 represents a homoplasious character state change for Eupegylis confusa, and character 14 , state 1 represents a nonhomoplasious character state change (synapomorphy) for the subtribe Pegylina (Fig. 1).

\section{Synonymy of Wernerophylla Lacroix, 2001 with Stenopegylis Arrow, 1943}

The variable placement of one species (Stenopegylis cylindrica Arrow, 1943) in two different tribes/ subtribes within the Melolonthinae indicates the value of phylogenetic analyses as a tool to understand relationships between taxa within taxonomic hierarchies. A priori taxa selection for this study warranted no rationale to include Wernerophylla nigra Lacroix, 2001 in the analysis or discussion. However, during examination of taxa for the study and wider literature on African melolonthines it became apparent that W. nigra (Pachydemini) is conspecific with S. cylindrica (Melolonthini). Therefore, their synonymy follows below.

\section{Stenopegylis Arrow, 1943}

Stenopegylis Arrow, 1943: 782-783. Lacroix 2010: 122-123.

cylindrica Arrow, 1943: 783-784. Lacroix 2010: 122-123.

\section{Wernerophylla Lacroix, 2001}

Wernerophylla Lacroix, 2001: 180-181. Lacroix 2007: 23-25, 211-212 (key), 223-225, 337, 397, 399 (Pachydemini catalogue). Syn. n.

nigra Lacroix, 2001: 181-183; Lacroix 2007: 224-225, 337. Syn. $\mathbf{n}$. 
Remarks. Arrow (1943) described Stenopegylis cylindrica from seven male and three female specimens from: Nyasaland, Mlanje, Dec. 1913, leg. Dr S.A. Neave. In a study of the Pachydemini of Kenya and Tanzania, Lacroix (2001) described Wernerophylla nigra as a monotypic genus using 11 male and two female specimens from 'Tanzania, Ruvuma Pr., near Songea, 9-13.XII.1997, leg. Werner \& Lizler'. I have examined Arrow's type series of S. cylindrica and specimens of the same locality series collected by Werner and Lizler used by Lacroix to describe W. nigra and there is no doubt that these taxa are conspecific in all respects. Lacroix (2007) includes W. nigra in his first catalogue of the genera and species of African Pachydemini, while Arrow's S. cylindrica is included in his second catalogue covering the non-Pachydemini genera and species of African Melolonthinae.

\section{Nomenclatural changes resulting from the analysis and character discussion}

The phylogenetic analysis aimed to resolve the relationship of species in the following genera: Adoretopsis, Hypopholis, Pegylis and Pegylidius and further to investigate the validity of the subtribe Pegylina which, prior to this study, included the following genera: Eupegylis, Hypopholis, Pegylis and Stenopegylis. In the analysis, four synapomorphies support the monophyly of the subtribe Pegylina, but only if the monotypic Stenopegylis is transferred to the Melolonthini sensu lato. Thus, to maintain a monophyletic Pegylina the genus Stenopegylis is removed from the subtribe Pegylina and moved to the Melolonthini sensu lato.

\section{Priority of Pegylis over Hypopholis}

Erichson (1847: 657) first mentioned Hypopholis followed by Pegylis in a key to new Melolonthini, and then again in the works (Erichson 1847) index. One could argue that as Hypopholis appears just before Pegylis it has line-priority over Pegylis, but from a page-priority perspective they appear on

\section{REFERENCES}

AHRENS, D. 2005. The phylogeny of Sericini and their position within the Scarabaeidae based on morphological characters. Systematic Entomology 31: 113-144.

AHRENS, D. \& VOGLER, A.P. 2008. Towards the phylogeny of chafers (Sericini): Analysis of alignmentvariable sequences and the evolution of segment numbers in the antennal club. Molecular Phylogenetics and Evolution 47: 783-798. the same page. Furthermore, to-date five species have been described in Hypopholis, while 30 species have been described in Pegylis, with the remaining two species originally being placed in Adoretopsis or Pegylidius (Appendix 1 provides a checklist). Thus, to correct their taxonomy, but at the same time maintain nomenclatural stability Pegylis is regarded as having been more widely used in the literature than Hypopholis, and thus Pegylis takes priority over Hypopholis.

The analysis and discussion provided above indicates that there is no justification for retaining Hypopholis as a genus, and thus Hypopholis is synonymized with Pegylis here, which introduces the following new combinations:

Pegylis sommeri (Burmeister, 1855) comb. n.;

P. uelensis (Burgeon, 1946) comb. n.,

P. vittata (Fåhraeus in Boheman, 1857) comb. $\mathbf{n}$.

A checklist of all the current taxa in the subtribe Pegylina is provided as Appendix 1. The newly reconstituted Pegylina includes two genera, i.e. Eupegylis Duvivier, 1892 (1 sp.) and Pegylis Erichson, 1847 (36 spp).

\section{ACKNOWLEDGEMENTS}

I thank all of the following: curators from the museums listed in Harrison (2014) for access to specimens and especially for the loan (M. Kerley $\mathrm{BMNH}$ ) and passage (M. Krüger TMSA) of the type series of Stenopegylis; Paul Schoolmeesters, M.L. Jameson and D. Keith for literature; A. Ballerio, A. Bezděk, A. Szitó, A.V. Evans, W. Warner, C.P.T.D. Gillett, D. Keith, E. Ricchiardi, G. Mynhardt and M.L. Jameson for information on the presence of a mesosternal process in other scarab taxa; M.J. Wingfield and C.H. Scholtz (both UP) provided NRF and Mellon Foundation funding, respectively; K. Balkwill's (WITS) writing retreats to the Jackson Field Station at WITS' Pullen Nature Reserve for writing time; and G. Goodman-Cron (WITS) and three anonymous reviewers for insightful comments that improved the paper.

ARROW, G.J. 1901. LI. - Remarks on secondary sexual differences in rutelid Coleoptera, with descriptions of some new forms. Annals and Magazine of Natural History 7(7): 393-401.

ARROW, G.J. 1902. XIX. - On rutelid and melolonthid beetles from Mashonaland and East Africa. Annals and Magazine of Natural History 9(7): 89-101.

ARROW, G.J. 1943. LXVI. - Systematic notes on the 
melolonthine beetles belonging to the genus Lepidiota and some related genera. Annals and Magazine of Natural History 10(11): 773-785.

BARAUD, J. \& BRANCO, T. 1990. Révision des Chasmatopterus Latreille, 1825. Coleopterological Monographs 1: 9-55.

BEZDĚK, A. 2004a. Catalogue of Diplotaxini of the Old World. Zootaxa 463: 1-90.

BEZDĚK, A. 2004b. Revision of the genus Ceratogonia Kolbe, 1899. Annales Zoologici 54(4): 797-801.

BOUCHARD, P., BOUSQUET, Y., DAVIES, A.E., ALONSO-ZARAZAGA, M.A., LAWRENCE, J.F., LYAL, C.H.C., NEWTON, A.F., REID, C.A.M., SCHMITT, M., SLIPINSKI, S.A. \& SMITH, A.B.T. 2011. Family-group names in Coleoptera. Zookeys 88: 1-972.

BRANCO, T. 2004. Description of a new species of Chasmatopterus Dejean, 1821, from Portugal, with a note on the subfamily Chasmatopterinae (Coleoptera: Melolonthidae). Elytron 17-18: 27-36.

BUNALSKI, M. 2002. Melolonthidae (Coleoptera: Scarabaeoidea) of the Palaearctic and Oriental Regions. I. Taxonomic remarks on some genera of Melolonthinae. Polskie Pismo Entomologiczne 71(4): 401-413.

BURGEON, L. 1946. Melolonthini et Pachydemini du Congo belge (suite) (Coleopt. Scarab. Melolonthinae). Revue de Zoologie et de Botanique africains, Bruxelles 39(4): 339-366.

BURMEISTER, H. 1855. Handbuch der Entomologie, Berlin. 4(2): 1-569.

COCA-ABIA, M.M. 2007. Phylogenetic relationships of the subfamily Melolonthinae. Insect Systematics $\mathcal{E}$ Evolution 38(4): 447-472.

DUVIVIER, A. 1892. Mélanges Entomologiques. X. Diagnoses de Coléoptères nouveaux du Congo. Annales de la Société Entomologique de Belgique 36: 56-60.

EDMONDS, W.D. \& ZÍDEK, J. 2004. Revision of the Neotropical dung beetle genus Oxysternon (Scarabaeidae: Scarabaeinae: Phanaeini). Folia Heyrovskyana Supplementum 11: 1-58.

ENDRÖDI, S. 1985. The Dynastinae of the world. Dr. W. Junk Publishers, The Hague as volume 28 in the Series Entomologica, Budapest, pp. 1-800; plates I-XLVI.

ERICHSON, W.F. 1847. Naturgeschichte des Insecten Deutschland. I. Coleoptera, Scarabaeides. Nicolaische Buchhandlung, Berlin. 1(3) parts 4-5: 481-800.

EVANS, A.V. 2003. A checklist of the New World chafers. Zootaxa 211: 1-458.

EVANS, A.V. \& SMITH, A.B.T. 2009. An electronic checklist of the New World Chafers (Coleoptera: Scarabaeidae: Melolonthinae). Version 3. Electronically published, Ottawa, Canada.

FÅHRAEUS in BOHEMAN, C.H. 1857. Insecta Caffrariae annis 1838-1845 a J.A. Wahlberg collecta, Coleoptera, Holmiae. 2: 1-395 + 1 plate.

GERSTAECKER, C.E.A. 1867. Beitrag zur Insekten-fauna von Zanzibar, nach dem während der Expedition des Baron v.d. Decken gesammelten Material zusammengestellt. Archiv für Naturgeschichte, Berlin 33(1): $1-49$.

GERSTAECKER, C.E.A. 1873. Die Gliedertier-Fauna des
Sansibar-Gebietes Decken C.C. Baron Carl Claus von der Decken's Reisen in Ost Afrikas, Berlin. 1-542.

GOLOBOFF, P.A., 1997. NONA Version 2.0 (for Windows). Computer software and documentation. Published by the author, Instituto Miguel Lillo, Miguel Lillo 205, 400 Sierra Madre de Tucuman, Argentina.

HARDY, C.R., LIPSCOMB, D.L., NIXON, K.C. \& OCHOTERENA, H. 2003. WinClada ver. 1.0, a basic user's manual. Available upon request from Kevin C. Nixon, Bailey Hortorium, 462 Mann Library, Cornell University, Ithaca, NY 14853, U.S.A. 1-29.

HARRISON, J.duG. 2004. Revision of the endemic southern African genus Rhabdopholis Burmeister, 1855 (Coleoptera: Scarabaeidae: Melolonthinae). African Entomology 12(1): 39-54.

HARRISON, J.duG. 2009. A taxonomic revision of the African leaf chafer genus Asthenopholis Brenske, 1898 (Coleoptera: Scarabaeidae: Melolonthinae): a SEM study. Zootaxa 2225: 1-48.

HARRISON, J. duG. 2014. Review of the South African species of Pegylis Erichson, 1847 (Coleoptera: Scarabaeidae: Melolonthinae) commonly known as large wattle chafers. African Entomology 22: 685-713.

HOLM, E. \& MARAIS, E. 1992. Fruit Chafers of Southern Africa (Scarabaeidae: Cetoniini). Ekogilde, Hartebeespoort, Pretoria, South Africa. 1-326 + 32 plates.

HOWDEN, H.F. 1954. A review of the genus Podolasia Harold (Coleoptera: Scarabaeidae). American Museum Novitates 1661: 1-11.

HOWDEN, H.F. 1997. Podolasiini, new tribe, and a revision of the included genera, Podolasia Harold and Podostena Howden, new genus (Coleoptera: Scarabaeidae: Melolonthinae). The Coleopterists Bulletin 51(3): 223-255.

JAMESON, M.L. 1997. Phylogenetic analysis of the sub-tribe Rutelina and revision of the Rutela generic groups. Bulletin of the University of Nebraska State Museum 14: 1-184.

JAMESON, M.L. \& WADA, K. 2004. Revision of the genus Peltonotus Burmeister (Coleoptera: Scarabaeidae: Dynastinae) from South-eastern Asia. Zootaxa 502: 1-66.

JAMESON, M.L. \& WADA, K. 2009. Five new species of Peltonotus Burmeister (Scarabaeidae: Dynastinae: Cyclocephalini) from Southeast Asia. Insecta Mundi 0102: 1-16.

KATOVICH, K. 2008. A generic-level phylogenetic review of the Macrodactylini (Coleoptera: Scarabaeidae: Melolonthinae). Insecta Mundi 23: 1-78.

KEITH, D. 2003. Le genre Brachyllus Brenske, 1896 en Chine. Nouvelles acquisitions pour la faune chinoise (Coleoptera, Melolonthidae). Bulletin de la Société Entomologique de France 108(3): 307-311.

KEITH, D. 2005. Remarque's taxonomiques sur quelques Rhizotroginae orientaux et description de nouvelles espèces (Col. Scarabaeoidea Melolonthidae). Symbioses 12: 23-32.

KEITH, D. 2007. Trios nouvelles espèces du genre Brachyllus Brenske, 1896 (Insecta: Coleoptera: Scarabaeoidea, Melolonthidae). In: Hartmann, M. \& Weipert, J. Biodiversität und Naturausstattung im Himalaya II: 419-424. 
KIM, J.1. 1996. Taxonomic study of Korean Rutelidae (Coleoptera) IV. Genus Mimela. Korean Journal of Entomology 26(3): 235-242.

KOLBE, H.J. 1894. Beiträge zur Kenntniss der Melolonthiden. I. Uebersicht der Melolonthinen, Leucopholinen und Schizonychen Africas. Annales de la Société Entomologique de Belgique 38(10): 548-577.

KRIKKEN, J. 1984. A new key to the suprageneric taxa in the beetle family Cetoniidae. Zoologische Verhandelingen Leiden 210: 1-75.

KUIJTEN, P.J. 1992. A revision of the genus Parastasia in the Indo-Australian Region (Coleoptera: Scarabaeidae: Rutelinae). Zoologische Verhandelingen Leiden 275: $1-176$.

LACROIX, M. 1989. Insectes Coléoptères Melolonthidae $\left(1^{\text {re }}\right.$ partie). Muséum National d'Histoire Naturelle, Paris. Faune de Madagascar 73(1): 1-302 + 785 figs.

LACROIX, M. 2001. Pachydeminae de l'Est Africain (Kenya et Tanzanie) (Coleoptera, Melolonthidae). Coléoptères 7(13): 173-226.

LACROIX, M. 2007. Pachydeminae du Monde (Scarabaeoidea, Melolonthidae). Genera et Catalogue Commenté. Collection Hannetons, Lacroix, Paris, France. $1-450+264$ plates.

LACROIX, M. 2010. Melolonthinae afrotropicaux (Coleoptera, Melolonthidae) Genera et Catalogue Commenté. $1-277+140$ plates \& figures +52 colour plates. Editions M., Lacroix, Paris, France.

MYNHARDT, G. \& WENZEL, J.W. 2010. Phylogenetic analysis of the myrmecophilous Cremastocheilus
Knoch (Coleoptera, Scarabaeidae, Cetoniinae), based on external adult morphology. ZooKeys 34: 129-140.

NIXON, K.C. 2002. WinClada ver. 1.00.08. Published by the author, Ithaca, New York, U.S.A.

NIXON, K.C. \& CARPENTER, J.M., 1993. On outgroups. Cladistics 9: 413-426.

PÉRINGUEY, L. 1904. Descriptive catalogue of the Coleoptera of South Africa (Lucanidae and Scarabaeidae). Transactions of the South African Philosophical Society 13: 1-293 + 4 plates.

PHILIPS, T.K., EDMONDS, W.D. \& SCHOLTZ, C.H. 2004. A phylogenetic analysis of the New World tribe Phanaeini (Coleoptera: Scarabaeidae: Scarabaeinae): hypotheses on relationships and origins. Insect Systematics \& Evolution 35(1): 43-63.

PRICE, D.L. 2007. A phylogenetic analysis of the dung beetle genus Phanaeus (Coleoptera: Scarabaeidae) based on morphological data. Insect Systematics E Evolution 38(1): 1-18.

PRICE, D.L. 2009. Phylogeny and biogeography of the dung beetle genus Phanaeus (Coleoptera: Scarabaeidae). Systematic Entomology 34(1): 137-150.

SMITH, A.B.T. 2006. A review of the family-group names for the Superfamily Scarabaeoidea (Coleoptera) with corrections to nomenclature and a current classification. Coleopterists Society Monograph 5: 144 204.

SMITH, A.B.T. 2008. South American Melolonthinae classification and nomenclature: some problems and solutions. Insecta Mundi 60: 1-28.

Accepted 15 April 2014 
Appendix 1. Revised checklist of the genera and species of Melolonthini: Pegylina Lacroix, 1989, following nomenclatural changes implemented here. An asterisk indicates taxa included in the phylogenetic study.

Genus Eupegylis Duvivier, 1892

confusa Duvivier, $1892^{*}$

Genus Pegylis Erichson, 1847

= Adoretopsis Fairmaire, 1887

= Hypopholis Erichson, 1847 (syn. n.)

= Pegylidius Péringuey, 1904

Type species: Pegylis morio Blanchard, 1850*

angolensis Moser, 1915*

bennigseni Brenske, 1898*

burgeoni Decelle, 1968*

conspurcata (Gerstaecker, 1867 - Hypopholis) *

ertli Moser, 1919*

gestroi Brenske, 1895*

giraudetae Decelle, 1968*

gracilis Burgeon, 1946

hauseri Brenske, 1898

kenyensis Decelle, 1968*

kigonserana Moser, 1919

lindiania Moser, 1919*

lineata Lacroix, 2008

lukulediana Moser, 1919

maculipennis Lansberge, 1882*

mashuna (Péringuey, 1904 - Pegylidius)*

microchaeta Moser, 1919*

morio Blanchard, 1850*

= brevior Fairmaire, 1884

neumanni Kolbe, 1894*

pilosa Lacroix, 2008*

pondoensis Arrow, 1943*

rufolineata Kolbe, $1894^{*}$

rufomaculata Linell, 1896*

salaama Brenske, 1898

salernei Lacroix, 2008

sommeri (Burmeister, 1855 - Hypopholis) comb. n. *

= sulcicollis (Boheman, 1857 - Hypopholis)

tchadensis Lacroix, 2008

tenuitarsis (Fairmaire, 1887 - Adoretopsis)*

uelensis (Burgeon, 1946 - Hypopholis) comb. n.*

ugandensis Lacroix, 2008

usambarae Brenske, 1898

vestita Brenske, 1895

vittata (Fåhraeus in Boheman, 1857 - Hypopholis) comb. n. *

werneri Lacroix, 2008

zavattarii Gridelli, 1940

(1 sp.)

(35 spp.) 